\title{
ENGINEERING DEVELOPMENT OF CERAMIC MEMBRANE REACTORSYSTEM CONVERTING NATURAL GAS TO HYDROGEN AND SYNTHESIS GAS FOR LIQUID TRANSPORTION FUELS
}

Monthly Status Report Period Ending: 04/31/1998

DOE Award NO.: DE-FC26-97FT96052--07 


\title{
ENGINEERING DEVELOPMENT OF CERAMIC MEMBRANE REACTOR SYSTEM FOR CONVERTING NATURAL GAS TO HYDROGEN AND SYNTHESIS GAS FOR LIQUID TRANSPORTATION FUELS
}

\author{
Monthly Status Report \\ April 1998
}

\section{Contract Objectives}

The objective of this contract is to research, develop and demonstrate a novel ceramic membrane reactor system for the low-cost conversion of natural gas to synthesis gas and hydrogen for liquid transportation fuels: the ITM Syngas process. Through an eight-year, three-phase program, the technology will be developed and scaled up to obtain the technical, engineering, operating and economic data necessary for the final step to full commercialization of the Gas-to-Liquids (GTL) conversion technology.

\section{Summary of Activity}

\section{Task 1.2 Materials and Seals Development}

\section{Task 1.2.1.1 Materials Characterization and Assessment}

At Eltron, construction began on six atmospheric-pressure, quartz test reactors. Furnaces and controllers were completed, and construction of the gas manifold and handling systems was initiated. Completion is expected at the end of June. The construction of an atmospheric pressure syngas test reactor continued at Air Products, and this is also expected to be completed in June. The gas feed to the reactors will be able to simulate the compositions expected in a commercial process.

Planning was begun for the tests to be carried out in the atmospheric screening reactors; the parameters to be incorporated into a Plackett-Burman type statistical experimental design were identified.

The development of additional brownmillerite compositions with improved physical properties was continued through the joint efforts of Ceramatec, Air Products and Eltron. The composition range was expanded, and He-impermeable samples of the new materials were prepared by Ceramatec. The materials were characterized by XRD, dilatometry and oxygen permeation at Air Products.

\section{Task 1.2.1.2 Powder Production and Test Sample Fabrication}

Work began at Ceramatec on scaling up the two powder compositions selected last month for powder production development. Small batches were prepared for calcining studies, with XRD analysis performed by Air Products. Preparation was begun of a 10-kg batch of the primary scaleup material, which will be used to fabricate the first high-pressure test samples. The dimensions of these samples were defined, and an initial high-pressure and -temperature seal system was selected.

\section{Task 1.2.1.3 Low $\Delta P(<300$ psig) Testing}


Construction of the hot-wall, 300-psig test reactors was continued at Eltron. The electrical infrastructure at Eltron was modified to supply the power required for the high-pressure reactors and associated equipment. Enclosures for the reactors, gas supplies and analytical equipment were constructed. The estimated date for commissioning the reactors is August.

Task 1.2.1.4 High $\triangle P(<500$ psig) Testing

Following the initial DHR, construction of the 500-psi cold-wall test reactor was begun at Air Products. Reactor enclosures and gas storage and supply systems were designed, and components were ordered. 